\title{
Reverse Knowledge Transfer in MNEs: Subsidiary Innovativeness and Entry Modes
}

\author{
Ram Mudambi, Lucia Piscitello, Larissa Rabbiosi
}

It is now well recognized that multinational enterprises (MNEs) are differentiated networks wherein subsidiaries vary in terms of their ability to create new knowledge and competencies for their parent groups. In much of this theory, it is taken for granted that subsidiary innovativeness has a positive correlation with the extent of reverse knowledge transfers to the parent MNE. Relying on the headquarterssubsidiary view of the MNE, we argue that, beyond a point, increasing subsidiary innovativeness will be associated with lower reverse knowledge transfers. Further, we argue that this relationship is sensitive to the subsidiary entry mode. Using data from a sample of 293 Italian subsidiaries, we find strong support for our hypotheses. In particular, our results confirm that the effect of subsidiary innovativeness on reverse knowledge transfers displays an inverted-U shape, and that the curvilinearity is greater for greenfield entries relative to acquisition entries. The U-shaped relationship between subsidiary innovativeness and reverse knowledge transfers, as well as the sensitivity of this result to entry mode are important new findings in the literature on the role of subsidiaries in competence creation.

\section{Introduction}

It is generally recognized that knowledge, and more specifically leveraging it across geographic boundaries, is the basis for the formation of sustainable competitive advantage in multinational enterprises (MNEs) (Grant, 1996; Kogut and Zander, 1993; Rugman and Verbeke, 2001; Tallman and Phene, 2007). The MNE's ability to undertake explorative R\&D (Mudambi and Swift, 2013) and mobilize the knowledge resources that exist within its network of subsidiaries is one of its key sour-ces of value creation (Bartlett and Ghoshal, 1989; Morck and Yeung, 1991; Narula, 2002). Knowledge transfer is a key aspect of knowledge mobilization and has been defined as the process through which one unit in an organization is affected by the experience of another and can be measured by changes in the knowledge of the recipient unit. In this paper, we study "reverse" knowledge transfers from subsidiary to parent, i.e., subsidiary experiences that are transferred to parent companies. These can be measured through changes in parent companies' knowledge stocks and entry into new technologies (Blomkvist et al., 2010; Dierickx and Cool, 1989).

Early literature on knowledge transfer was based on the home-centric view of the MNE wherein knowledge flowed from the parent to its subsidiaries (e.g., Porter, 1990; Vernon, 1966). More recent literature recognized the critical importance of strategically locating and leveraging knowledge resources from subsidiaries (Bartlett and Ghoshal, 1989; Benito et al., 2003; Criscuolo and Narula, 2007; Frost and Zhou, 2005; Nielsen and Michailova, 2007; Zander, 1999). However, the MNE is a differentiated network within which subsidiaries vary widely in terms of their roles and responsibilities (Nohria and Ghoshal, 1994). Some MNE subsidiaries have evolved through headquarters' mandates, as well as through their own entrepreneurial initiatives, to undertake a greater range of substantial creative roles in their parent organizations (Birkinshaw and Hood, 1998; Blomkvist et al., 2010). Other subsidiaries concentrate on more traditional tasks, exploiting the competencies of their parent firms in their local country environments (Kuemmerle, 1999).

A substantial body of research in international business has investigated the relationship between a range of subsidiary characteristics and reverse knowledge transfers (e.g., Ambos et al., 2006; Gupta and Govindarajan, 2000; Håkanson and Nobel, 2000; Rabbiosi, 2011; Yang et al., 2008). However, we claim this literature has not adequately distinguished between the ability of a subsidiary to engage in reverse knowledge transfers and its actual willingness to do so. Failing to recognize the possibility of subsidiary pursuit of its local interests rather than the global interests of its parent MNE can lead to systematic overestimates of the extent of reverse knowledge transfers associated with subsidiary innovativeness. This also suggests that in order to fully exploit competence-creating subsidiary mandates, it is necessary to implement strategies to minimize the extent of incentive misalignment between headquarters and subsidiaries (Ghoshal and Nohria, 1989). 
Parent companies incur the costs of reverse knowledge transfers because these transfers are expected to drive new value creation (Ambos et al., 2006; Mudambi, 2008; Subramaniam and Venkatraman, 2001). The costs of knowledge transfer and the nature of the relationship between the source and the target have direct implications for the extent of rents generated through the knowledge transfer. Therefore we cannot fully investigate the factors influencing reverse knowledge transfer without recognizing that subsidiary innovativeness can have both positive and negative effects on reverse knowledge transfers.

Viewing the MNE from the headquarters-subsidiary perspective, we argue that subsidiary innovativeness has a positive correlation with the extent of reverse knowledge transfers to the parent MNE up to a certain point, beyond which increasing subsidiary innovativeness will be associated with lower reverse knowledge transfers. Further, we argue that this relationship is sensitive to subsidiary entry mode. We test our conceptual model using data from a sample of 293 Italian subsidiaries, and find strong support for our hypotheses. Our results confirm that the effect of subsidiary innovativeness on reverse knowledge transfers displays an inverted-U shape, and that the curvilinearity is greater for greenfield entries relative to acquisition entries. The U-shaped relationship between subsidiary innovativeness and reverse knowledge transfers as well as the sensitivity of this result to entry mode are important new findings in the literature on competence-creating subsidiaries.

The paper is organized as follows. We begin by highlighting the theoretical questions explored in our study. Then, we develop our theoretical model and explain how it advances the existing theory with regard to MNE knowledge management processes. Our theory development leads to the specification of a set of research hypotheses relating reverse knowledge transfers to subsidiary innovativeness. In the following sections we describe our data, estimation methodology, and empirical results. Finally, we discuss the implications of our findings for knowledge management in MNEs and relate them to the wider literature on headquarter-subsidiary relationships.

\section{Theoretical background}

To an increasing extent, the success of MNEs is considered to be contingent upon the ease and speed with which knowledge is disseminated throughout the organization (Bartlett and Ghoshal, 1989; Gupta and Govindarajan, 2000). Foreign direct investment (FDI) resulting in the formation of foreign subsidiaries has become an important means of spurring the dynamic process of learning and competence creation within the MNE (Cantwell and Piscitello, 1999; Cantwell and Piscitello, 2000). There has been a growing awareness among scholars that this process enables MNEs to augment their competitive advantages and/or to create new advantages (Kuemmerle, 1999; Pearce, 1999). Specifically, the increased role of geographically dispersed sourcing of technology through the international networks of globally integrated MNEs has led to a growing interest in the asset-acquiring motive for FDI (Cantwell and Piscitello, 2000; Narula, 2002). It is becoming recognized that the observed decentralization in the management of international R\&D can be related to the capture of "home base augmenting" benefits (Kuemmerle, 1999; Papanastassiou and Pearce, 1997; Pearce, 1997) through the development of subsidiary specific advantages (Rugman and Verbeke, 2001) and advantages stemming from collocation with and embeddedness in the local innovation system (Narula and Santangelo, 2009).

The MNE is a complex network firm that is characterized by "multiple embeddedness" (Meyer et al., 2011) as well as “competence-creating overlaps" (Kappen, 2011). It typically includes subsidiaries with a wide variety of roles in knowledge creation. At one extreme are subsidiaries that exploit and adapt capabilities that are already familiar to their parent companies. Such subsidiaries can be characterized as adaptors of the MNE's existing products and processes to local environments (Dunning and Narula, 1995). The absolute amount of knowledge-related activities in such subsidiaries is often quite large and in general is associated with the volume of local sales (Cantwell and Mudambi, 2005). This knowledge is often relevant for other MNE units, generating reverse knowledge transfers (Ambos et al., 2006). At the other extreme are subsidiaries that explore and access knowledge resources and skills in order to improve the whole firm's competence base. Foreign subsidiaries with such explorative mandates are able to create entirely new sets of competencies that can be used throughout the MNE network (Cantwell and Piscitello, 1999). Competence-creating subsidiaries generate and develop new knowledge assets (new products, technologies, practices, skills, etc.) that become sources of value creation for the MNE as a whole (Benito et al., 2003; Papanastassiou and Pearce, 1997; Zander, 1998). This knowledge can be transferred and utilized by other subsidiaries and by the parent company as well (e.g., Cantwell and Mudambi, 2005). Further, the center of excellence literature has documented that subsidiaries, whose knowledge is used by other units within the parent organization, gain influence within the MNE network (Holm and Pedersen, 2000).

However, headquarters has a major role in ensuring that reverse knowledge transfers take place. Indeed, the literature has recognized that subsidiaries are severely limited in their ability to undertake reverse knowledge transfers within the firm without the cooperation of headquarters (Forsgren and Pedersen, 2000; Holm and Pedersen, 2000), and that headquarters involvement significantly improves reverse knowledge transfer performance (Ciabuschi et al., 2011; Dellestrand, 2011).

Recognizing the key role of headquarters, it has been argued that reverse knowledge transfers occur through subsidiaries persuading the parent firms that their knowledge is relevant (Yang et al., 2008). Ambos et al. (2006) report a complementary finding, that such transfers require parent companies that are committed to learn from their subsidiaries and willing to recognize the potential benefits of subsidiaries' knowledge. Recent research has shown that headquarters attention to subsidiary units is influenced by aspects that typically characterize competence-creating subsidiaries, factors such as the unit's existing or potential contribution to the MNE as a whole, through initiative-taking and profile-building (Bouquet and 
Birkinshaw, 2008). It has also been argued that subsidiaries active in standardized downstream functions are viewed as less important to corporate headquarters (Schulz, 2001).

However, as pointed out by Mudambi and Navarra (2004), there are two sides to this coin. A subsidiary which competencies are recognized by the headquarters as being extremely valuable for the corporate group can exercise power simply by withholding these from the parent MNE. Hence, while the non-use of these competencies restricts the subsidiary's intraMNE influence, it also imposes costs on the parent group. The extent of subsidiary power and influence depends on the outcome of the implied bargaining game (Mudambi and Navarra, 2004). It is clear that the greater the costs imposed on the MNE by the non-use of the subsidiary's competencies, the more power and influence the headquarters is willing to concede to the subsidiary.

Differentiating between a subsidiary "ability" and "willingness" to engage in reverse knowledge transfers opens a new perspective on these results. The extent of subsidiary innovativeness affects not only its ability to persuade headquarters but also affects the attention paid by the latter. Thus, subsidiaries with lesser levels of innovativeness may have a high willingness but a low ability to engage in reverse knowledge transfer. In contrast, subsidiaries with greater level of innovativeness may have a high ability but perhaps a lower level of willingness to transfer knowledge to their parents.

This ability-willingness dichotomy is likely to be exacerbated when we incorporate insider-outsider effects (Cantwell and Mudambi, 2011; Lorenzen and Mudambi, 2013) that can be generated by entry mode. A stream of literature in headquartersubsidiary relations has argued that some subsidiaries are deeply embedded in the corporate network while others remain outsiders (Monteiro et al., 2008). It has been further argued that greenfield subsidiaries are more likely to be insiders in the corporate system as compared to acquisitions that typically have larger numbers of executives and managers socialized in the network of the prior corporate parent. Recent research has shown that the differences between greenfield and acquired subsidiaries are extremely long-lasting and persist even when examining the records of MNEs over periods as long as a century (Blomkvist et al., 2014).

This discussion raises some important research questions in the context of competence-creating subsidiaries. In the following section, we develop a framework within which we set up a logical set of hypotheses. These are based on the two basic theoretical foundations we have developed here. First we examine the general effects of the ability-willingness dichotomy on reverse knowledge transfers. Next we study the contextual effects of the entry mode on this relationship.

\section{Hypotheses development}

The transfer of knowledge from a foreign subsidiary to its parent company can take place when the subsidiary has a stock of knowledge that is valuable for the MNE. This seems a trivial matter. Therefore, at the first glance, the higher the level of innovativeness of the subsidiary, the more knowledge will be available in the subsidiary that can be transferred to the parent company and the greater will be the levels of reverse knowledge transfer. However, it is less trivial to expect that the level of reverse knowledge transfer will increase monotonically.

Our hypotheses are anchored within the stream of literature on headquarters-subsidiary relationships within the MNE organization. Different theoretical lenses have been used in this field of inquiry and these lead to different predictions with regard to the behavior of the parties in the relationship. Headquarters can be viewed as a positive resource or a negative hindrance (Foss et al., 2012; Mudambi, 2011), while subsidiary behaviors can vary over a substantial range. At one extreme, social identity theory predicts that the MNE is characterized by a high degree of cohesiveness, so it functions as a social community and subsidiaries work selflessly for the good of the firm as a whole (Kogut and Zander, 1993). At the other extreme, agency theory predicts that it is characterized by rent seeking, so that subsidiaries act in their own interests, completely neglecting the success of the wider MNE (Mudambi and Navarra, 2004).

We argue that both of the forces of social community and agency are likely to be present within any MNE. The relative impact of these two forces on subsidiary behavior will depend on the relative attractions that they confer. If the subsidiary's innovativeness is very low, it has very little to gain from withholding its knowledge from headquarters. Hence, it is likely to be very willing to engage in reverse knowledge transfers. However, its ability to attract headquarters attention (Bouquet and Birkinshaw, 2008) is quite low. As subsidiary innovativeness increases, it is more likely to attract the notice of headquar-ters, so reverse knowledge transfers increase. This generates a positive relationship between subsidiary innovativeness and reverse knowledge transfers.

However, as subsidiary innovativeness continues to increase, raising headquarters attention and awareness, the benefits available to the subsidiary by exercising its power also increase. Research on intra-MNE knowledge transfer has highlighted that control of knowledge can represent a lever for bargaining power in the MNE (Gupta and Govindarajan, 2000). Thus, the governance of reverse knowledge transfer is a way to exercise power in relation to the parent company (Mudambi and Navarra, 2004; Palmie and Keupp, 2014). On the one hand, transferring knowledge can be equivalent to diminishing this power since no exclusive control of knowledge assets can be exercised once the subsidiary knowledge is available to the parent company. On the other hand, in a dynamic context in which subsidiary and parent company are involved in lengthy relations and repeated dealings, it is also justified to assume that subsidiaries gain power by continuously transferring their knowledge (Foss and Pedersen, 2002), while maintaining the threat of cutting off the flow. We argue that at some point, these temptations undermine the intra-MNE forces of cohesiveness.

Thus, the relationship between subsidiary innovativeness and reverse knowledge transfers is subject to balancing the effects of social community and agency. At low levels of subsidiary innovativeness, the social cohesiveness of the MNE ensures 
that the relationship is positive. However, as subsidiary innovativeness continues to increase, the benefits available to the subsidiary by pursuing its own interests increase concomitantly, strengthening the forces of agency. At very high levels of subsidiary innovativeness, further increases in innovativeness are associated with declines in the extent of reverse knowledge transfers.

We develop a second line of argument based on subsidiary resource use. The higher the degree of innovativeness of the focal subsidiary the less we expect it to engage in reverse knowledge transfer due to the resource allocation problem. A central argument of the managerial theory of the firm is that managers allocate scarce resources to a range of tasks (Spulber, 2009). We expect that subsidiaries showing very high degrees of innovativeness will allocate resources largely towards issues related to knowledge generation, and that a wide variety of procedural and communication channels will be created and used for the specific issues related to knowledge creation. At the same time, maintaining channels for innovation requires diverting re-sources from the specific requirements of intra-MNE knowledge transfer. Therefore, we expect to find that if a subsidiary has a high focus on knowledge creation it is likely to exhibit lower reverse knowledge transfer. In contrast, subsidiaries with lower levels of innovativeness will allocate resources largely towards issues related to the transfer of the knowledge they have, and that a wide variety of procedural and communication channels will be created and used for the specific issues related to intra-MNE knowledge transfer.

Taken together, our arguments suggest that the aggregate relationship between the subsidiary role in the creation of knowledge - the degree of subsidiary innovativeness - and the level of reverse knowledge transfer will be non-monotonic. Specifically, although there is a positive relationship between innovativeness and reverse knowledge transfer, at very high levels of innovativeness, the relationship becomes negative. Therefore, we predict:

Hypothesis 1: There exists an inverted U-shaped relationship between subsidiary innovativeness and the level of reverse knowledge transfers (RKT).

In international management research, the idea that each MNE unit is part of both an internal corporate network and an external network (e.g., customers, suppliers, local universities) is well established (e.g., Ghoshal and Nohria, 1989; Hedlund, 1986; Meyer et al., 2011). Parent firm and subsidiary management can attempt to maximize internal integration. However, parent management has less control over the subsidiary's managerial attempts at external integration. Additionally, independent of the managerial actions of parents and subsidiaries, differences in the internal and external network embeddedness of subsidiaries also exist because of subsidiary-specific characteristics such as its mode of establishment (Anand, 2011; Rabbiosi and Santangelo, 2013). Accordingly, we expect the relationship between the level of subsidiary innovativeness and the levels of reverse knowledge transfer to vary between greenfield and acquired subsidiaries.

First, it is helpful to consider the differences between the level and nature of integration in the corporate network between the two types of subsidiaries. A greenfield subsidiary is a newly-created unit but within the boundaries of the MNE. Lan-guages, cultures and routines compatible with the organizational characteristics of the parent company have existed ever since its establishment. In contrast, acquired subsidiaries are new entrants into the MNE corporate network that already have well-established cultures, routines, and patterns of behavior. They are likely to inherit their knowledge integration mecha-nisms from their operational existence prior to their acquisition (Anand, 2011). The presence of similar and shared cognitive schema, integration mechanisms and routines has been found to positively influence knowledge flows (Ghoshal et al., 1994; Gupta and Govindarajan, 2000; Noorderhaven and Harzing, 2009; Tsai, 2002). In this respect, ceteris paribus, greenfield subsidiaries are superior in sharing knowledge with their parents than acquired units, as the latter need more resources to integrate into the MNE internal network as well as to overcome the negative effect of incompatibilities based on their history (Anand, 2011).

Second, innovative capabilities of foreign subsidiaries have been explained by higher degrees of local embeddedness and subsidiaries' ability to tap into local knowledge bases (Andersson et al., 2002; Cantwell, 1995; Cantwell and Mudambi, 2011). However, the relationship between subsidiary embeddedness and its innovative capabilities critically depends on the entry mode employed (Anand, 2011; Anand and Delios, 2002). Greenfield and acquired subsidiaries differ in terms of their evolution towards knowledge creation (Blomkvist et al., 2014). Greenfield subsidiaries start as de novo activities in a foreign market using knowledge that has been developed by their MNE parent. As time passes, a certain number of these subsidiaries can become more embedded in the host country and increasingly self-sufficient in knowledge creation (Cantwell and Mudambi, 2005) and can contribute to the competitive advantage of the MNE with a higher degree of innovativeness. Others continue to exploit the home-based technological advantage and provide basic levels of knowledge. Conversely, at the time of their integration into the MNE network, acquired subsidiaries have generally already had time to accumulate relationships with the existing external local networks and to develop knowledge that leverages their local embeddedness (Anand and Delios, 2002; Håkanson and Nobel, 2001).

The above discussion implies two complementary arguments as to why the relationship between subsidiary innovativeness and reverse knowledge transfer has a more pronounced inverted-U shape in greenfield subsidiaries than in acquisitions. The argument focuses on highly innovative subsidiaries, since this is where the difference between the two entry modes is likely to be the most pronounced.

The first reason relates to subsidiary managers' ability to engage in reverse knowledge transfers. In order to reach a stage of high innovativeness (and competence-creation), and contribute to their parents' competitive advantage, subsidiaries need to tap into the local country-specific advantages, a process that is time consuming and uncertain (Rabbiosi and Santangelo, 2013). However, in order to do this, they need to become insiders within the local knowledge network (Cantwell and 
Mudambi, 2011). Acquired subsidiaries are typically already locally embedded; indeed, their local network is often the reason for their acquisition. They are also usually mature units whose competence-creating capabilities are reasonably advanced. In contrast, greenfield units are faced with multiple tasks in developing competence-creating capabilities, so they often take time to mature. Greenfield units need to a) develop a local network, often from scratch; b) work at the integration of local and corporate knowledge to develop new competencies; c) invest heavily in procedural and communication channels for the specific requirements of reverse knowledge transfers. Managers at greenfield units that succeed in becoming highly inno-vative are likely to find themselves resource-constrained in the sense of Penrose (1959). Their counterparts at acquired, equally innovative, units are likely to have been able to devote more time, effort and resources to the development of reverse knowledge transfer capabilities.

The second reason relates to subsidiary managers' willingness to engage in reverse knowledge transfers. The entry mode through which a subsidiary has been established can also affect the subsidiary's internal legitimacy and therefore it's ability to pursue power. In arguing for Hypothesis 1, we explained that increasing levels of reverse knowledge transfer can be instrumental in building perceptions that the subsidiary's knowledge is needed within the MNE. In this way, subsidiaries achieve legitimacy in the eyes of the parent. However, just as greenfield and acquired subsidiaries differ in terms of their internal and external network relationships, both in terms of level and pattern of evolution, they differ in their internal legitimacy in a like manner.

Greenfield units are likely to have managers "whose ties and identification with the parent group go back longer" (Cantwell and Mudambi, 2005, p. 1115), whereas the managers of an acquired group tend to be associated with a different corporate culture (Sambharya, 1996). Thus, ceteris paribus, greenfield subsidiaries are more likely to exhibit higher levels of internal legitimacy, and they are part of what has been called the "in crowd of subsidiaries" (Monteiro et al., 2008, p. 93). On the other hand, acquired subsidiaries may find it more difficult to gain headquarters' attention and are more likely to become isolated (Bouquet and Birkinshaw, 2008).

Accordingly, the described substitution effect between legitimacy and the levels of reverse knowledge transfer is likely to be lower for acquired subsidiaries than for greenfields. In other words, at the same level of innovativeness, acquired subsidiaries display less degree of internal legitimacy than greenfield units. Therefore they need to "buy" further legitimacy within their new parent MNE. Hence, in the intra-MNE competition for resources and mandates, acquired subsidiaries have to engage in higher levels of reverse knowledge transfer to overcome their legitimacy disadvantage relative to greenfield units.

Taken together, our arguments suggest that reverse knowledge transfers differ systematically between greenfield and acquired subsidiaries. At low level of innovativeness, greenfield subsidiary's shared cognitive structure, language and culture with the parent company ensures that it is able to generate higher levels of reverse knowledge transfers than an equally innovative acquired subsidiary. However, at very high levels of innovativeness, the greater resource requirements of greenfield managers as well as their favored insider status within the MNE mean that they have both lower ability and lower willingness to match the reverse knowledge transfers of equally innovative acquired subsidiaries. Accordingly, we predict that:

Hypothesis 2: The curvilinearity of the inverted U-shaped relationship will be greater for greenfields than for acquired subsidiaries.

\section{Methods}

\section{Sample and data collection}

The sample frame used is the population of all Italian MNEs with more than 50 employees and operating in manufacturing industries. The sample comes from the Reprint database ${ }^{1}$, which contains census data on the foreign activities of Italian firms. As of the beginning of 2004, it consists of a total of 358 manufacturing Italian MNEs with at least one majority-owned subsidiary located in advanced countries and involved in "primary upstream activities" such as R\&D and manufacturing.

Out of these 358 MNEs, 84 were studied through face-to-face structured interviews with the parent company's top managers (response rate of about 24 percent). The top managers were variously titled as president, managing director, or general manager. ${ }^{2}$ The interviews, which lasted 120-180 minutes each, were conducted from December 2004 to July 2005 and involved six researchers. During the interviews, the respondents went through a pre-tested questionnaire, and interviewers took notes to ensure accurate recording of the responses. For each of the 84 MNEs, we collected data about all their majority-owned foreign subsidiaries involved in manufacturing or R\&D activities. Of these MNEs, about 80 percent reported five or fewer subsidiaries. We arranged longer interviews with the parent company managers for MNEs that reported more than five subsidiaries. After accounting for missing data, we have information on 293 parent company-subsidiary dyads. All

\footnotetext{
${ }^{1}$ The dataset Reprint is sponsored by the ICE-Italian Trade Promotion Agency; it is developed and updated yearly at Politecnico di Milano. It provides a census of the Italian firms with foreign activities, and contains the following information: (i) corporate name and address of the head office, for both the Italian parent companies and their foreign affiliates; (ii) the code of the industrial activity, and other relevant economic variables (the dimensional class in terms of employees and turnover) for the Italian parent companies; (iii) the year and the type of participation in each foreign affiliate participated by Italian firms (e.g. greenfield vs. acquisition, wholly/control/minority ownership).

${ }^{2}$ In December 2004, we began the data collection process by contacting parent companies' top managers by telephone and sending them a personalized letter with the description of the project, the assurances regarding the confidentiality of collected data and a formal request for a face-to-face interview.
} 


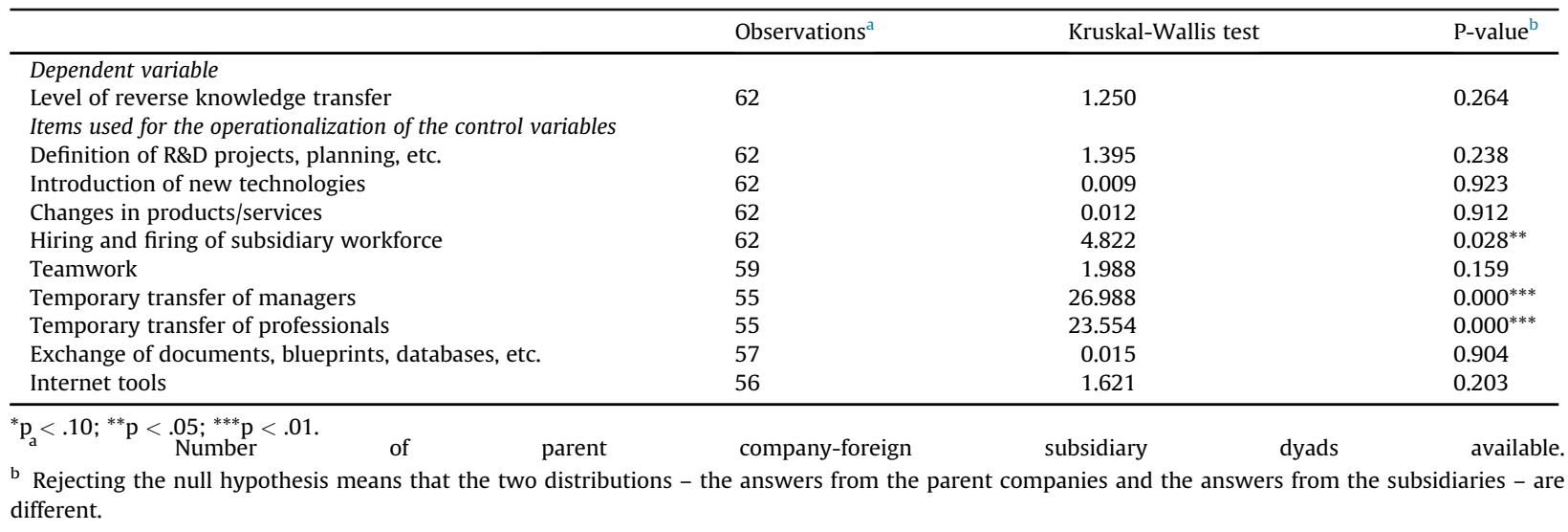

the hypotheses introduced above are articulated in the context of the parent company-foreign subsidiary dyad, and this was the context used for the empirical tests.

We undertook several procedures to minimize the possibility of common method bias.

The survey incorporated the following set of procedural remedies. First, the measurement of the dependent and the explanatory variables was separated. During the in-depth face-to-face interviews, such a separation was accomplished by introducing a time lag between the measurement of the two sets of variables (Podsakoff et al., 2003). Secondly, Podsakoff et al. (2003, p. 884), suggest that the use of Likert scales with similar anchors may "increase the possibility that some of the covariation observed among the constructs examined may be the result of the consistency in the scale properties rather than the content of the items". Accordingly, we chose to use different scale endpoints and formats for the different variables. In particular, our dependent variable, i.e., reverse knowledge transfer, is on a 4 point scale $(0-3)$. The independent variable capturing the levels of innovativeness of the subsidiary is an index operationalized using nine questions, each eliciting a dichotomous response. The control variables capturing the transfer mechanisms are on a 7 point Likert scale, while the control variable for subsidiary autonomy is on a 5 point Likert scale. These remedies are expected to reduce biases caused by commonalities in scale endpoints and anchoring effects. Finally, the information used for defining the entry mode and the remaining control variables are objective measures and collected through secondary sources. These variables cannot be influenced by common method variance.

We performed the Harman single-factor test (Harman, 1967) on the items included in our econometric model to examine whether common-method bias augmented relationships. If common-method bias exists in the data, a single factor will emerge from a factor analysis of all measurement items included in the study, or one general factor that accounts for most of the variance will result. The factor analyses reported good properties, supporting the validity of the data. Specifically, nine factors emerged with eigenvalues greater than one. The first factor (eigenvalue $=3.57$ ) explained $13.21 \%$ of the variance, while the cumulative variance explained by all the nine factors was $63.40 \%$.

As a further test for common method bias, and to rule out possible one-respondent bias, we also surveyed a sub-sample of subsidiaries' top managers. If parent company managers answered the questions driven by "implicit theories", "social desirability", or the "consistency effect" (Podsakoff et al., 2003), thus leading to common method bias, we would expect the answers obtained from the parents' managers to statistically differ from those obtained from the subsidiaries' managers. For instance, we might expect a parent to under-estimate the degree of autonomy and the importance of a focal subsidiary, and the focal subsidiary to over-estimate its autonomy and importance compared to the parent's evaluation. Out of the 293 dyads, we were able to collect 62 usable questionnaires from the subsidiaries. We performed validity response tests on the responses from the two ends of the knowledge conduit - the MNE parent and the subsidiary. Regarding our dependent variable, the Kruskal-Wallis equality of populations rank test (Brett et al., 1995; Downey et al., 1975) confirmed that the responses from managers at the MNE parent and at the subsidiary were not significantly different. In general, we found a similar result concerning the items used for the operationalization of the control variables, with only three exceptions (see Table 1).

Finally, we examined non-response bias by comparing the 84 MNE respondents with the non-respondents within the overall sample frame of 358 MNEs. Non-respondents were compared to respondents in terms of size (class of number of employees), area of location of the parent company in Italy, and innovation sector (Pavitt, 1984; Pavitt, 1990). ${ }^{3}$ Regarding size and parent company location, no statistically significant differences between respondents and non-respondents were found. However, the two groups differ in terms of innovation sector: our sample is overrepresented in science-based $(p<0.1)$ and specialized-supplier sectors ( $<0.05$ ), while it is underrepresented $(\mathrm{p}<0.001)$ in supplier-dominated sectors (see Table 2 ).

\footnotetext{
${ }^{3}$ According to Pavitt $(1984 ; 1990)$, five technological trajectories can be identified: supplier-dominated, specialized-supplier, science-based, scaleintensive and information-intensive. These different trajectories reflect differences in the main sources of technology.
} 


\begin{tabular}{|c|c|c|c|c|}
\hline & $\begin{array}{l}\text { Sample frame } \\
\mathrm{N}=358 \text { MNEs }\end{array}$ & $\begin{array}{l}\text { Non respondent } \\
\mathrm{N}=274 \text { MNEs }\end{array}$ & $\begin{array}{l}\text { Respondent } \\
\mathrm{N}=84 \mathrm{MNEs}\end{array}$ & $\chi^{2}$ test \\
\hline \multicolumn{5}{|c|}{ Parent company's sectors } \\
\hline Science based & 44 & 29 & 15 & $0.0757^{\dagger}$ \\
\hline Specialized suppliers & 65 & 42 & 23 & $0.0122^{*}$ \\
\hline Scale intensive & 163 & 125 & 38 & 0.9765 \\
\hline Supplier dominated & 86 & 78 & 8 & $0.0003^{* *}$ \\
\hline \multicolumn{5}{|l|}{ Parent company's size } \\
\hline $50-249$ & 98 & 80 & 18 & 0.1624 \\
\hline $250-499$ & 81 & 66 & 15 & 0.2325 \\
\hline $500-5000$ & 145 & 102 & 43 & $0.0225^{*}$ \\
\hline$>5000$ & 34 & 26 & 8 & 0.9924 \\
\hline \multicolumn{5}{|c|}{ Parent company's location area } \\
\hline North West & 202 & 149 & 53 & 0.1587 \\
\hline North East & 109 & 82 & 27 & 0.6994 \\
\hline Centre & 40 & 36 & 4 & $0.0330^{*}$ \\
\hline South - Islands & 7 & 7 & 0 & 0.1390 \\
\hline
\end{tabular}

${ }^{\dagger} \mathrm{p}<.10 ;{ }^{*} \mathrm{p}<.05 ;{ }^{* *} \mathrm{p}<.01 ;{ }^{* * *} \mathrm{p}<.001$.

One reason for the small number of firms in the supplier-dominated sectors could be that most of the MNEs investing abroad in such sectors do not consider reverse knowledge transfer from their subsidiaries to be an important issue. In fact, there is evidence that firms in supplier-dominated sectors have a much lower tendency to engage in reverse knowledge transfer from their subsidiaries, since foreign technology is generally obtained from outside the firm's boundaries (Brusoni et al., 2001; Mudambi et al., 2004). On the other hand, firms in science-based and specialized supplier sectors, like elec-tronics, pharmaceuticals, machinery and instruments, have a higher tendency to transfer knowledge in this fashion. These are also the most innovative sectors in terms of most objective indicators like patents and the number of science-industry interactions.

Table 2 also shows that the bulk of parent companies in our sample are located in the northwest of Italy (68\%), an area that includes Piedmont and Lombardy, the two most important Italian regions in terms of industrial production. The rest of the parent companies are mainly situated in the northeast part of Italy (27\%). Very few parent MNEs are located in the center or south of Italy. This picture is in line with the overall distribution of Italian MNEs and their FDI as in 2004 (see Mariotti and Mutinelli, 2005). Italian MNEs, although among the largest firms in Italy, remain relatively smaller than their counterparts in other major industrialized countries. This is reflected in our sample where 90\% of the MNEs have less than 5000 employees. Additionally, especially in the most recent period, small and medium sized enterprises have become important actors within the "club" of the Italian multinational investors; this is also captured in our sample where 35\% of MNEs have less than 500 employees. Therefore, we argue that our sample composition is reflective of the underlying population.

\section{Measures}

Following Schulz (2001), we identified three general domains of knowledge through informal interviews with a pilot sample of parent company heads ${ }^{4}$ before the beginning of the larger study. ${ }^{5}$ The first knowledge domain was knowledge regarding products, such as knowledge about product design and architecture, product development, know-how of materials, qualitative and quantitative characteristics, and so forth. The second domain was knowledge regarding technologies, such as process know-how, engineering, and technology development. The last domain captured knowledge pertaining to primary activities of the foreign subsidiary (such as logistics, distribution, operations, marketing, and sales).

The dependent variable of this study, reverse knowledge transfer, is operationalized by the degree of use of the foreign subsidiary's knowledge (aggregated across knowledge domains) as perceived by the parent company (e.g., Gupta and Govindarajan, 2000). Respondents were first asked to provide descriptions of the products, technologies, and primary activities of the foreign subsidiary using open-ended questions. Next, the respondents were asked to answer questions focusing on whether the identified subsidiary's knowledge pertaining to the above three domains was transferred to and used by the parent company. ${ }^{6}$ Finally, the respondents were asked to aggregate the subsidiary's knowledge across the identified domains

\footnotetext{
${ }^{4}$ These firms operate in medium and high technology intensive sectors (chemicals, biomedicals, synthetic fibers, and automotive components) and they have production and R\&D facilities in several countries all over the world. These firms were used in constructing the pilot sample because there were strong a priori expectations of them being involved in reverse knowledge transfer. Accordingly, we expected these firms to provide a good benchmark in the subsequent analysis of the wider sample.

${ }^{5}$ These interviews helped us to refine the research instrument and to evaluate how parent companies perceive and comprehend knowledge as well as the knowledge transfer process. The interview results also enabled us to develop some illustrative examples that were used to clarify issues for respondents in the larger study.

${ }^{6}$ Examples of these questions are: has the subsidiary's technology that you described been transferred to and used by the parent company? Have the specific subsidiary's competencies that you described been transferred to and used by the parent company?
} 
and indicate the intensity of the knowledge transfer from the subsidiary to the parent company. This last response was used to define the dependent variable - reverse knowledge transfer - that ranges from 0 (no transfer at all) to 3 (high transfer).

We think a particularly strong aspect of our data set is that it also includes dyads where no transfer has taken place. Ignoring cases where reverse knowledge transfer $=0$ would introduce selection bias, a problem that has been overlooked in many previous studies of knowledge transfer. As recently pointed out, "most of the existing literature tends to focus on identifying the barriers and facilitators of knowledge transfers from the perspective of those subsidiaries that are already involved in knowledge transfer activities - colloquially known as the 'in crowd' - and disregards the group of subsidiaries that is simply isolated from any knowledge-transfer activity within the MNC" (Monteiro et al., 2008, p. 91).

In order to test our hypotheses, we first need to operationalize the role of subsidiaries in the creation of knowledge - i.e., the subsidiary's level of innovativeness. We define the level of innovativeness of a subsidiary in terms of the subsidiary's activity structure, specifically the extent of its knowledge creation responsibilities (Cantwell and Mudambi, 2005). Respondents were asked to provide "yes" or "no" answers to a set of nine questions indicating whether the focal foreign subsidiary was devoted to (i) activities aimed at the creation of new products and/or new technologies and/or any competence new to the MNE (technological as well as others); (ii) activities directed towards significant improvements of products and/or technologies and/or any competence already existing in the MNE; (iii) activities directed towards marginal improvements of products and/or technologies and/or any competence already existing in the MNE. Examples of these questions are: 1 ) "Has the foreign subsidiary $j$ developed products new to the MNE?"; 2 ) "Has the foreign subsidiary $j$ made significant improve-ments to products already existing in the MNE?"; 3 ) "Has the foreign subsidiary $j$ made marginal improvements to products already existing in the MNE?" The variable subsidiary innovativeness is an index defined as a weighted average of responses to the nine questions where the most complex innovation (new to the MNE) was given a weight of 4 , the intermediately complex innovation (significant improvements) was given a weight of 2 , and the least complex innovation (marginal improvements) was given a weight of 1 . While other studies have grouped subsidiaries into different classes based on their innovative behavior (e.g., Ambos and Schlegelmilch, 2007; Ghoshal and Nohria, 1989; Rabbiosi, 2011), our operationalization has the advantage of measuring innovativeness on a continuum.

In order to capture the moderation effects of the entry mode on the relationship between subsidiary innovativeness and reverse knowledge transfer (Hypothesis 2), we built the dummy variable acquisition that equals 1 for foreign subsidiaries that were acquired; it is zero otherwise.

A number of variables have been considered to control for other factors affecting reverse knowledge transfer. First of all, since a small subsample of subsidiaries is the result of majority owned joint ventures (JVs), we define the dummy variable joint venture to capture this entry mode. It should be noted that in all the subsidiaries in our sample, the Italian parent has a controlling interest. Subsidiaries that are not the result of an acquisition or a joint venture have been established through a greenfield investment. Secondly, we control for possible confounding effects related to the location of the subsidiary through the variable cultural distance measured using Kogut and Singh's (1988) cultural distance index, and the variable publication intensity defined as the scientific and technical journal articles published in the host country (source: World Bank), normalized by the population of the country (figures at 2005).

The variable subsidiary age is the difference between 2005 (year when the interviews were conducted) and the year when the subsidiary became a part of the Italian MNE. The relevant information was obtained from the respondents during the interviews and checked through secondary data such as articles, publications, firms' announcements, and so on. As previous research indicates, absorptive capacity can play a role in explaining reverse knowledge transfer (Ambos et al., 2006; Gupta and Govindarajan, 2000). Accordingly, we defined the dummy variable activity similarity to capture knowledge familiarity between senders and receivers. It equals one when the parent company and foreign subsidiary produce similar products, or are involved in similar research and development activities.

We control for the extent to which different knowledge transfer mechanisms are employed within the parent companysubsidiary relationship (Björkman et al., 2004; Gupta and Govindarajan, 2000; Schulz, 2001). We set up a 7-point Likert scale, from "used rarely" to "used very often". Following Rabbiosi (2011), we built the variable personal coordination as the average of the responses based on managers' specifications of the extent to which teamwork mechanisms involving people from both the units of the firm, temporary (short-term) transfers of managers within the parent-subsidiary dyad, and temporary (short-term) transfers of scientific and technical staff (researchers, engineers, etc.) within the parent-subsidiary dyad, were used (Cronbach's alpha $=0.72$ ). The managers also rated the frequency of the utilization of electronic in-struments - such as e-forums, videoconferencing, instant messaging, etc. - and the sharing of handbooks, blueprints, da-tabases, etc. The variable electronic-based coordination is computed as the average of the responses to the above items (Cronbach's alpha $=0.61)^{7}$

Subsidiary autonomy can affect both the innovativeness of the foreign subsidiary (Ghoshal and Bartlett, 1988; Venaik et al., 2005) and the occurrence and the intensity of knowledge transfer within an MNE (Björkman et al., 2004; Schulz, 2001). Accordingly, following the operationalization of Ghoshal et al. (1994), we included a measure of subsidiary autonomy constructed from an instrument that captured the allocation of strategic decision-making to the foreign subsidiary. Based on a 5

\footnotetext{
7 Given the value of the Cronbach's alpha below 0.70, we verified the loadings of the items running an explorative factor analysis that provided the following results. Factor loadings: utilization of electronic instruments $=0.85$; sharing of handbooks, blueprints, databases $=0.85$; eigenvalue $=1.45$; variance explained $=73 \%$.
} 
Descriptive statistics and correlations (293 observations)

\begin{tabular}{|c|c|c|c|c|c|c|c|c|c|c|c|c|c|c|c|c|}
\hline & Mean & s.d. & (1) & (2) & (3) & (4) & (5) & (6) & (7) & $(8)$ & (9) & (10) & $(11)$ & $(12)$ & (13) & $(14)$ \\
\hline (1) Reverse knowledge transfer & 0.61 & 1.01 & & & & & & & & & & & & & & \\
\hline (2) Subsidiary autonomy & 9.99 & 3.11 & 0.07 & & & & & & & & & & & & & \\
\hline (3) Relative size & -1.71 & 1.20 & 0.15 & -0.08 & & & & & & & & & & & & \\
\hline (4) Subsidiary sales & 0.05 & 0.15 & 0.10 & -0.07 & 0.30 & & & & & & & & & & & \\
\hline (5) High-tech industries & 0.40 & 0.49 & 0.01 & 0.05 & -0.23 & -0.18 & & & & & & & & & & \\
\hline (6) Publication intensity & 0.00 & 0.00 & 0.10 & 0.14 & 0.01 & 0.11 & 0.05 & & & & & & & & & \\
\hline (7) Cultural distance & 1.16 & 0.92 & -0.07 & -0.13 & -0.07 & -0.17 & -0.01 & -0.33 & & & & & & & & \\
\hline (8) Subsidiary age & 9.57 & 6.77 & 0.00 & 0.12 & -0.02 & 0.03 & 0.08 & 0.09 & -0.22 & & & & & & & \\
\hline (9) Activity similarity & 0.88 & 0.32 & -0.02 & -0.31 & 0.03 & 0.08 & -0.07 & -0.10 & 0.11 & 0.02 & & & & & & \\
\hline (10) Personal coordination & 3.21 & 1.81 & 0.29 & -0.28 & 0.12 & 0.10 & -0.18 & -0.13 & 0.14 & -0.09 & 0.25 & & & & & \\
\hline (11) Electronic-based coordination & 4.53 & 2.11 & 0.20 & 0.02 & -0.10 & -0.01 & 0.22 & -0.03 & 0.03 & 0.08 & -0.12 & 0.21 & & & & \\
\hline (12) Acquisition & 0.59 & 0.49 & 0.00 & 0.00 & 0.22 & 0.17 & -0.06 & 0.26 & -0.19 & -0.18 & -0.05 & 0.02 & -0.12 & & & \\
\hline (13) Joint-venture & 0.11 & 0.31 & -0.08 & -0.07 & -0.09 & -0.02 & -0.05 & -0.25 & 0.17 & -0.06 & 0.06 & -0.08 & -0.09 & -0.41 & & \\
\hline (14) Subsidiary innovativeness & 3.35 & 3.91 & 0.39 & 0.17 & 0.25 & 0.10 & 0.10 & 0.30 & -0.15 & -0.06 & -0.25 & -0.16 & 0.03 & 0.22 & -0.11 & \\
\hline (15) Subsidiary innovativeness ${ }^{2}$ & 26.47 & 43.60 & 0.24 & 0.11 & 0.12 & 0.04 & 0.17 & 0.15 & -0.10 & -0.06 & -0.28 & -0.15 & -0.03 & 0.20 & -0.11 & 0.75 \\
\hline
\end{tabular}

Correlations greater than 0.09 are significant at least at $p<0.10$. The variable subsidiary innovativeness and its squared term have been centered on their mean value in order to avoid high correlations between interaction terms and interacting variables. The table lists the means and standard deviations of these variables prior to the centering.

point scale ${ }^{8}$, the following question was posed to the parent company's top management with regard to each foreign subsidiary: "Please indicate the extent of the subsidiary's autonomy in making the following decisions: 1) definition of R\&D projects, planning, resources, etc.; 2) introduction of new technologies; 3) changes in products/services; and 4) hiring and firing of the subsidiary workforce." The final measure is the average of responses to the four items (Cronbach's alpha $=0.74$ ).

Several studies (e.g., Gupta and Govindarajan, 2000; Minbaeva, 2007; Williams, 2007) have already shown that subsidiary size may influence knowledge transfer. Larger subsidiaries should be more likely to offer non-duplicative knowledge to parent companies. However, the effect of subsidiary size may in part be a function of the size of its parent company, so that relative rather than absolute size can be expected to matter. Thus, we defined relative size as measured by the difference between the natural logarithm of the subsidiary's number of employees and the natural logarithm of the parent company's number of employees, as in 2004. We also defined subsidiary sales as the sales (in million of Euros) of the subsidiary, as in 2004. We controlled for the industry, as foreign subsidiaries operating in different industries may face different opportunities with regard to reverse knowledge transfer. Specifically, it is expected that these opportunities are likely to be greater in medium-high technology intensive sectors where distinctive subsidiary knowledge can be of more use and interest for the parent company. Therefore, using the taxonomy developed by Pavitt (1984), we defined the dummy variable high-tech industries that equals one if the subsidiary operates either in science based or specialized suppliers sectors. Low-technology intensive sectors are the benchmark.

\section{Results}

Table 3 shows the descriptive statistics and correlations for the variables used in the analyses. We found evidence of reverse knowledge transfer in 93 of our sample of 293 parent company-foreign subsidiary dyads, which corresponds to an overall incidence of about 32\%. In particular, 26 dyads reported reverse knowledge transfer to be "high", 35 dyads reported it to be "medium", and 32 dyads reported it to be "low". Although the above picture seems to suggest that parent firms continue to serve as the most active creator and diffuser of knowledge within the MNE $(68 \%$ of the subsidiaries never transferred knowledge to their parent companies), our dataset gives evidence of the less obvious transfer of knowledge existing in foreign affiliates to the MNE's home operations. This evidence allowed us to qualify the effects of subsidiary characteristics - degree of innovativeness and entry mode - on reverse knowledge transfer in MNEs. In our sample, 89 subsidiaries have been estab-lished through a greenfield investment, 173 have been acquired, while the remaining 31 come from majority-owned JVs.

Results from the ordered probit estimations are reported in Table 4. The STATA 12 econometric software package was used to perform these estimations. The relevant marginal effects are reported in the Appendix. In order to control for heteroskedasticity and obtain robust variance estimates, we used the Huber/White sandwich estimator. Likewise, we corrected the estimated standard errors and the variance-covariance matrix of the estimators for clustering on MNEs. This controls for the fact that the observations are independent across MNEs, but not necessarily within each MNE.

As shown in Model $1^{9}$, the coefficients for the variable subsidiary innovativeness and its squared term are statistically significant and positive $(\mathrm{p}<.01)$ and negative $(\mathrm{p}<.05)$, respectively. These results support Hypothesis 1 and indicate that the

\footnotetext{
${ }^{8}$ We used a 5 level scale where: 1 ) the parent company decides alone; 2 ) the parent company decides but considers subsidiary inputs; 3 ) both parent company and subsidiary have roughly equal influence on decision; 4) the subsidiary decides, but considers parent company suggestions; 5 ) the subsidiary decides alone.

${ }^{9}$ The mean values of the variance inflation factor of Model 1 and 2 based on linear regression analyses are 1.48 and 3.42, respectively.
} 
Results of ordered probit analyses of reverse knowledge transfer

\begin{tabular}{|c|c|c|c|c|c|c|c|c|c|c|}
\hline & \multirow{2}{*}{\multicolumn{2}{|c|}{$\frac{\text { Test of HP1 }}{\text { Model } 1}$}} & \multirow{2}{*}{\multicolumn{2}{|c|}{$\frac{\text { Test of HP2 }}{\text { Model } 2}$}} & \multicolumn{6}{|l|}{ Robustness checks } \\
\hline & & & & & Model 3 & & Model 4 & & Model $5^{\mathrm{a}}$ & \\
\hline Subsidiary autonomy & $0.03(0.04)$ & & $0.03(0.04)$ & & $0.04(0.04)$ & & $0.04(0.04)$ & & $0.03(0.04)$ & \\
\hline Relative size & $0.08(0.07)$ & & $0.09(0.07)$ & & $0.09(0.07)$ & & $0.10(0.07)$ & & $0.09(0.08)$ & \\
\hline Subsidiary sales & $-0.13(0.38)$ & & $-0.10(0.38)$ & & $-0.21(0.36)$ & & $-0.26(0.36)$ & & $-0.06(0.37)$ & \\
\hline High-tech industries & $-0.05(0.29)$ & & $0.00(0.29)$ & & $-0.01 \quad(0.28)$ & & $-0.01 \quad(0.28)$ & & $0.06(0.29)$ & \\
\hline Publication intensity & $-70.47 \quad(549.87)$ & & $-104.20(544.65)$ & & $-120.41(546.75)$ & & $-116.10(548.00)$ & & $91.53(548.15)$ & \\
\hline Cultural distance & $-0.15(0.13)$ & & $-0.15(0.13)$ & & $-0.14(0.12)$ & & $-0.14(0.12)$ & & $-0.17(0.13)$ & \\
\hline Subsidiary age & $0.00(0.01)$ & & $0.00(0.02)$ & & $0.00(0.01)$ & & $0.00(0.01)$ & & $0.00(0.02)$ & \\
\hline Activity similarity & $0.30(0.27)$ & & $0.35(0.27)$ & & $0.29(0.27)$ & & $0.28(0.27)$ & & $0.14(0.25)$ & \\
\hline Personal coordination & $0.30(0.09)$ & $* * *$ & $0.32(0.09)$ & $* * *$ & $0.32(0.09)$ & $* * *$ & $0.32(0.09)$ & $* * *$ & $0.32(0.09)$ & $* * *$ \\
\hline Electronic-based coordination & $0.10(0.06)$ & & $0.09(0.06)$ & & $0.10(0.06)$ & & $0.10(0.06)$ & & $0.08(0.06)$ & \\
\hline Acquisition & $-0.37(0.18)$ & $* *$ & $-0.64(0.25)$ & $* * *$ & $-0.34(0.18)$ & $*$ & $-0.34(0.18)$ & $*$ & $-0.68(0.26)$ & $* * *$ \\
\hline Joint-venture & $-0.21(0.35)$ & & $-0.23(0.35)$ & & $-0.04(0.50)$ & & $-0.25(0.36)$ & & $-0.22(0.35)$ & \\
\hline Subsidiary innovativeness & $0.24(0.04)$ & $* * *$ & $0.33(0.07)$ & $* * *$ & $0.22(0.04)$ & $* * *$ & $0.23(0.04)$ & $* * *$ & $0.35(0.07)$ & $* * *$ \\
\hline Subsidiary innovativeness ${ }^{2}$ & $-0.01 \quad(0.01)$ & $* *$ & $-0.03(0.01)$ & $* * *$ & $-0.01 \quad(0.01)$ & $*$ & $-0.01 \quad(0.01)$ & $*$ & $-0.03(0.01)$ & $* * *$ \\
\hline $\begin{array}{l}\text { Acquisition } \times \text { Subsidiary } \\
\text { innovativeness }\end{array}$ & & & $-0.12(0.07)$ & $*$ & & & & & $-0.15(0.07)$ & $* *$ \\
\hline $\begin{array}{l}\text { Acquisition } \times \text { Subsidiary } \\
\text { innovativeness }{ }^{2}\end{array}$ & & & $0.03(0.01)$ & $* *$ & & & & & $0.03(0.01)$ & $* *$ \\
\hline $\begin{array}{l}\text { Joint-venture } \times \text { Subsidiary } \\
\text { innovativeness }\end{array}$ & & & & & $0.28(0.13)$ & $* *$ & $0.19(0.06)$ & $* * *$ & & \\
\hline $\begin{array}{l}\text { Joint-venture } \times \text { Subsidiary } \\
\text { innovativeness }{ }^{2}\end{array}$ & & & & & $-0.03(0.03)$ & & & & & \\
\hline N. of observations & 293 & & 293 & & 293 & & 293 & & 272 & \\
\hline Log-pseudolikelihood & -226.99 & & -225.21 & & -224.94 & & -225.22 & & -203.09 & \\
\hline Wald $\chi^{2}$ & $82.41^{* * *}$ & & $93.37^{* * *}$ & & $129.96^{* * *}$ & & $149.77^{* * *}$ & & $95.94^{* * *}$ & \\
\hline McFadden's Adjusted Pseudo- $\mathrm{R}^{2}$ & 0.202 & & 0.209 & & 0.210 & & 0.209 & & 0.211 & \\
\hline
\end{tabular}

In brackets are robust standard errors corrected for heteroskedasticity and cluster-correlated data. ${ }^{*} \mathrm{p}<.10 ;{ }^{* *} \mathrm{p}<.05$; ${ }^{* * *} \mathrm{p}<.01$ (two-tailed tests applied).

a The $25 \%$ of the youngest greenfield subsidiaries have been removed from the sample.

probability that an MNE parent company receives higher levels of knowledge from a subsidiary increases with the subsidiary innovativeness but the relationship is not monotonic. From Figure 1, it can be seen that the point where subsidiary innovativeness appears to have negative consequences for reverse knowledge transfer is at 8.92 on a normalized scale for subsidiary innovativeness (range: $-3.32 ;+11.68$ ).

Hypothesis 2 predicts that, compared to acquired subsidiaries, greenfield subsidiaries exhibit a greater curvilinearity of the inverted U-shaped relationship between levels of reverse knowledge transfer and subsidiary innovativeness. Examining the estimates of the coefficients of the interaction terms of the variable acquisition with the variable subsidiary innovativeness and its squared term, we note that they are negative $(\mathrm{p}<.10)$ and positive $(\mathrm{p}<.05)$ respectively and both significant $($ Model 2 ). Figure 2 shows the relationship between subsidiary innovativeness and the level of reverse knowledge transfer for subsidiaries established via greenfield and those that have been acquired. We can observe that for greenfield subsidiaries the point where subsidiary innovativeness appears to have negative consequences for reverse knowledge transfer is at 4.88 on a

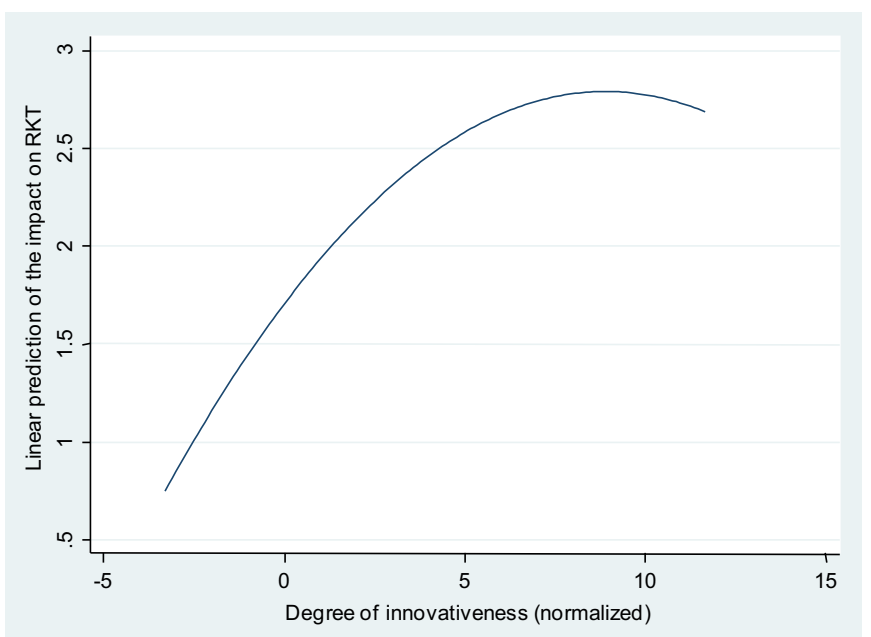

Figure 1. Plotting the marginal ridge line based on Model 1 


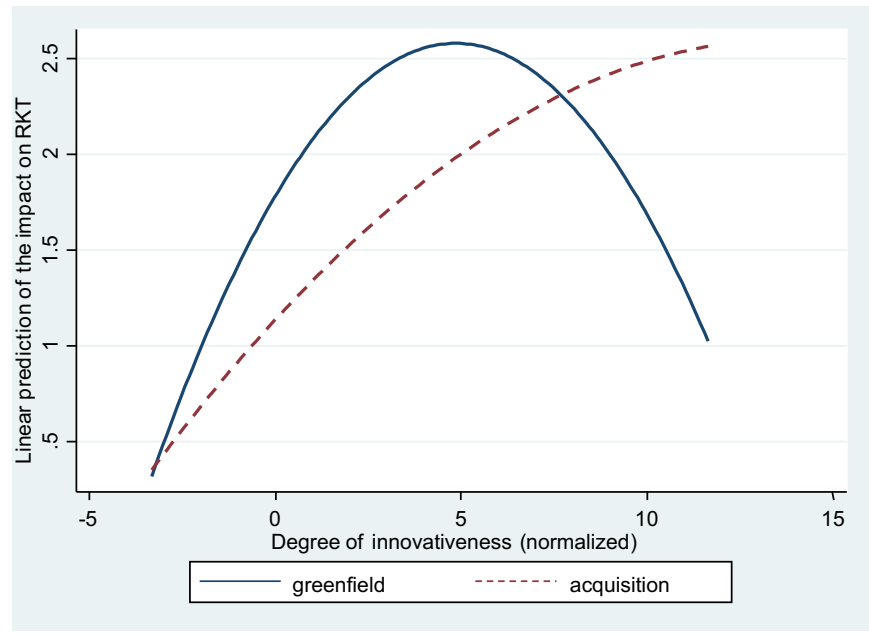

Figure 2. Plotting the marginal ridge line based on Model 2

normalized scale for subsidiary innovativeness, while the tipping point calculated for acquired subsidiaries is 13.95 . We conclude that the data provide support for Hypothesis 2.

\section{Robustness tests}

We undertook a series of tests to examine the robustness of our results. First, our results are based on the two extreme entry modes of greenfield and acquisition (Blomkvist et al., 2014). As there are intermediate or mixed entry modes, the latter are likely to fall in between the two extreme entry modes we study here. Accordingly, in our first robustness test, we estimated our models for JVs.

The JV benefits from the established internal network brought from the parent company but also from an established external network due to the presence of the partner. Thus, while JV's enjoy some internal legitimacy, often proportional to their parent's level of commitment, they are likely to be less insiders in the corporate network than greenfield subsidiaries for the same reasons argued above. Our expectation is that the difference between greenfield and JVs will be less stark than that between greenfields and acquisitions. In Model 3, the coefficient of the variable joint-venture $\times$ subsidiary innovativeness is positive and significant $(\mathrm{p}<.05$ ) while the coefficient of the interaction term of the variable joint-venture with the squared term of the variable subsidiary innovativeness is not significant. Accordingly, JVs appear to moderate the curvilinearity of the inverted U-shaped relationship between levels of reverse knowledge transfer and subsidiary innovativeness only linearly. In Model 4 we therefore re-estimate the moderation effect of JVs on the U-shaped relationship adding to the model only the interaction term of the variable joint-venture with subsidiary innovativeness. The results of Models 3 and 4 confirm our expectation, supporting the arguments we advance regarding the effects of internal legitimacy within the MNE.

Second, we are concerned that the relatively small number of extremely innovative subsidiaries may drive our results. Accordingly, we re-estimate Models 1 and 2 (Table 4) on a series of sub-samples of parent-subsidiary dyads, successively dropping the most innovative subsidiaries from the data set. The new results and the shape of the curves represented in Figures 1 and 2 remained consistent with the findings based on the full sample.

Finally, it is possible that over time, greenfield subsidiaries may become more locally embedded. Hence, our results may be driven by the lack of local embeddedness of the youngest greenfield subsidiaries. Further, there may be an implicit assumption that greenfield subsidiaries are young while acquisitions are older operations. We study this possibility by generating estimates using sub-samples created by eliminating successively younger greenfield parent-subsidiary dyads. Firstly, we estimated Model 2 (Table 4) considering a subsample in which the $25 \%$ of the youngest greenfield subsidiaries (five years old or younger) have been removed. The results are reported in Model 5 (Table 4). Secondly, we reduced further the age of greenfield subsidiaries removing the $50 \%$ youngest ones (nine years old or younger). In both cases, the results resemble those of Model 2. This suggests that the effects of entry mode on reverse knowledge transfers persist for long periods of time. This finding is in concordance with the findings reported by Blomkvist et al. (2014).

\section{Discussion and conclusion}

In this paper, we study reverse knowledge transfer in MNEs and link it to subsidiary innovativeness. In much of the literature on competence-creating subsidiaries, there is the implicit assumption that subsidiary specific advantage is translated directly into competitive advantage for the MNE. This approach can be traced to the Kogut and Zander's (1993) conception of the MNE as a "social community". In this view, cooperation arises as a dominant strategy for subsidiaries that are socialized to work for the good of the firm as a whole. A contrasting view of the MNE is that of subsidiary rent- 
seeking, wherein subsidiaries act as self-interested agents serving a disconnected headquarters (Mudambi and Navarra, 2004). In reality, both the forces of the social community and rent-seeking are at play (Mudambi, 2011), which is what we attempt to examine empirically in this paper.

Additionally, based on the conception of the MNE as a differentiated network (Nohria and Ghoshal, 1994), we argue that subsidiaries differ both in terms of the extent to which they are embedded in the local milieu as well as in the corporate network. Our analysis complements the work of Andersson et al. (2007) who model the MNE as a federation, a social community policed by headquarters' monitoring of the subsidiary's local embeddedness. Thus, while Andersson et al. (2007) analyze differences in the extent of local embeddedness, we examine different levels of corporate embeddedness. We believe that taken together these two studies advance our understanding of the complex nature of individual subsidiaries (Rugman et al., 2011) as well as the "multiple embeddedness" nature of the MNE (Meyer et al., 2011).

An implication of this argument is that the antecedents of subsidiary embeddedness affect the relationship between subsidiary innovativeness and reverse knowledge transfer. Drawing on the rich literature on entry modes (e.g., Brouthers and Hennart, 2007), we posit that greenfield subsidiaries are likely to be better embedded in the MNE network than acquisitions, with joint ventures falling in between these two. This is due to the fact that greenfield entries tend to have a much greater representation of top managers who are socialized within the MNE community. Correspondingly, the entry mode literature documents that greenfield entries tend to be less embedded in the local business environment. The analysis is precisely reversed in the case of acquisition entries. Acquired subsidiaries usually have a pre-existing history in the local environment, either as independent units or as subunits within another parent. Consequently they are often outsiders within the corporate network, subject to the problems of isolation (Monteiro et al., 2008) and legitimacy (Cantwell and Mudambi, 2005).

At low levels of subsidiary innovativeness, a greenfield subsidiary's disadvantages in terms of its lack of local embeddedness and its de novo status are outweighed by its familiarity with the parent MNE's operational routines. In contrast, acquisitions have very little knowledge "currency' with which to overcome their legitimacy deficit. Hence, at low levels of subsidiary innovativeness, greenfield subsidiaries perform better in terms of reverse knowledge transfer. However, at high levels of innovativeness, a greenfield subsidiaries need to expend significant resources on the three tasks of creating embeddedness in local innovation networks, integrating knowledge from their parent MNEs and recombining these with local knowledge to create new competencies. Facing this "multiple task problem" means that they cannot invest resources in their internal innovation network to same extent as an equally innovative acquired unit. This is because the latter can devote virtually its entire resources to the single task of recombining MNE knowledge and local knowledge to create new competencies.

Our results complement previous works that have highlighted the direct influence of entry modes on reverse knowledge transfer (e.g., Anand, 2011; Håkanson and Nobel, 2001) showing that entry modes can also play an important contingency role. Previously Rabbiosi and Santangelo (2013) have shown how entry modes impinge on the relationship between parents' benefits from reverse knowledge transfer and subsidiary age. Our findings add to these results showing that the influence of subsidiaries' innovativeness on the levels of reverse knowledge transfer is also likely to vary depending on subsidiary entry mode.

From the perspective of managers, our study points to the importance of recognizing that the forces of agency and rent seeking are likely to be strongest in the most innovative subsidiaries. Hence, it is important to design, develop and implement routines and incentive structures to ameliorate these effects and not assume that the benign forces of social identity will prevail. Further, managers should recognize the effect of subsidiary entry mode when drawing up expectations of the extent of reverse knowledge transfer. It is important to recognize the different drivers of reverse knowledge transfers in greenfield subsidiaries and acquisitions. It has been documented that acquisitions tend to be more contributive to the innovative ca-pabilities of the MNE (Blomkvist et al., 2014), but our study indicates that this result can stem from both ability as well as willingness to transfer knowledge. Hence it is very important to set up incentives to dull the negative effects of agency, particularly in greenfield subsidiaries.

Our findings may be counter-intuitive for headquarters managers who may feel closer to their counterparts at greenfield subsidiaries, since they are typically easier to communicate with due to a shared corporate culture and sometimes even a pre-existing history of shared personal connectivity (Lorenzen and Mudambi, 2013). In contrast, the absence of these factors may make managers at acquired units difficult to communicate with. Our study highlights that for highly innovative subsidiaries, headquarters' managers should recognize that there may be high levels of willingness to transfer knowledge in acquired subsidiaries and that these may be the most promising sources of reverse knowledge transfers. In other words, it may pay to look beyond the obvious "ability" dimension.

Finally, in our control effects, we point to the consistently strong positive effect of "personal coordination". This points to the key role of micro-foundations (Foss et al., 2012). Knowledge transfer decisions are taken at the level of individual managers and strongly influenced by their personal relationships (Lorenzen and Mudambi, 2013). Thus, recognizing the key role of creative individuals in designing and implementing incentives in crucial to successful reverse knowledge transfer.

As with all research, this study has limitations. First, we relied heavily on data from a survey administered through an interview. This raises concerns regarding key informant bias and common method bias. Accordingly, we took several steps in both the design and testing phases to limit these concerns. However, future work should move toward developing survey instruments in which different respondents are used for collecting information relative to dependent and independent variables. Second, we based the definition of subsidiary innovativeness based on perceptual data. Although it is inherently difficult to operationalize such a dimension using objective measures it would be useful to further enhance these 
measurements and develop more elaborate measures. For instance, Mudambi and Swift $(2011,2013)$ use objective measures including patents and new product releases. Finally, we based our empirical analyses on cross-sectional data. While our results are consistent with the theoretical predictions, further longitudinal research should be undertaken to bolster empirically the causal claims of our model. Moreover, this study analyzed reverse knowledge transfer in the dyadic context. This is recognized to be better than nodal analysis (e.g., Gupta and Govindarajan, 2000). However, a superior approach would be an analysis in the "systemic" context. Such an approach would allow us to study the occurrence of knowledge transfer within the full spectrum of the MNE's network relationships (Meyer et al., 2011).

We believe that our work offers several suggestions for future research on the strategic role of subsidiaries in competence creation. In particular, while much of the innovation management literature studies subsidiary innovativeness and the creation of knowledge and competencies, and much of international business literature studies reverse knowledge transfers, we believe this paper constitutes one of the first attempts at building a bridge between these two literatures and opens new avenues for research. Since MNE parents are the orchestrators of subsidiary level innovativeness and they are particularly interested in reverse knowledge transfers, our results suggest a rationale for using the acquisition rather than greenfield entry. While entry mode is a critical choice made by MNE parents within the headquarter-subsidiary relationship, there are other important decision dimensions like national and sub-national location, the nature of transferred knowledge, the nature of communication medium used and so on. While we have controlled for many of these dimensions, future research should develop theory and estimation methodologies to explain their effects on the relationship between subsidiary's competence creation and reverse knowledge transfers.

\section{Appendix}

Table A1

Marginal effects

\begin{tabular}{|c|c|c|c|c|c|c|c|c|c|c|c|c|}
\hline & \multicolumn{4}{|l|}{ Model 1} & \multicolumn{4}{|c|}{ Model 2 (greenfield = 1 ) } & \multicolumn{4}{|c|}{ Model 2 (acquisition $=1$ ) } \\
\hline & $\mathrm{RKT}=0$ & $\mathrm{RKT}=1$ & $\mathrm{RKT}=2$ & $\mathrm{RKT}=3$ & $\mathrm{RKT}=0$ & $\mathrm{RKT}=1$ & $\mathrm{RKT}=2$ & $\mathrm{RKT}=3$ & $\mathrm{RKT}=0$ & $\mathrm{RKT}=1$ & $\mathrm{RKT}=2$ & $\mathrm{RKT}=3$ \\
\hline Subsidiary autonomy & -0.0084 & 0.0009 & 0.0023 & 0.0052 & -0.0084 & 0.0009 & 0.0023 & 0.0052 & -0.0084 & 0.0018 & 0.0029 & 0.0037 \\
\hline Relative size & -0.0210 & 0.0022 & 0.0058 & 0.0129 & -0.0210 & 0.0022 & 0.0058 & 0.0129 & -0.0210 & 0.0044 & 0.0072 & 0.0093 \\
\hline Subsidiary sales & 0.0000 & 0.0000 & 0.0000 & 0.0000 & 0.0234 & -0.0025 & -0.0065 & -0.0144 & 0.0234 & -0.0049 & -0.0081 & -0.0104 \\
\hline High-tech industries ${ }^{a}$ & -0.0007 & 0.0001 & 0.0002 & 0.0004 & -0.0007 & 0.0001 & 0.0002 & 0.0004 & -0.0007 & 0.0001 & 0.0002 & 0.0003 \\
\hline Publication intensity & 25.5777 & -2.7076 & -7.0987 & -15.7713 & 25.5777 & -2.7076 & -7.0987 & -15.7713 & 25.5618 & -5.4016 & -8.8169 & -11.3434 \\
\hline Cultural distance & 0.0366 & -0.0039 & -0.0102 & -0.0226 & 0.0366 & -0.0039 & -0.0102 & -0.0226 & 0.0366 & -0.0077 & -0.0126 & -0.0163 \\
\hline Subsidiary age & -0.0006 & 0.0001 & 0.0002 & 0.0004 & -0.0006 & 0.0001 & 0.0002 & 0.0004 & -0.0006 & 0.0001 & 0.0002 & 0.0003 \\
\hline Activity similarity $^{\mathrm{a}}$ & -0.0835 & 0.0116 & 0.0256 & 0.0463 & -0.0835 & 0.0116 & 0.0256 & 0.0463 & -0.0800 & 0.0196 & 0.0286 & 0.0318 \\
\hline Personal coordination & -0.0780 & 0.0083 & 0.0217 & 0.0481 & -0.0780 & 0.0083 & 0.0217 & 0.0481 & -0.0780 & 0.0165 & 0.0269 & 0.0346 \\
\hline $\begin{array}{l}\text { Electronic-based } \\
\text { coordination }\end{array}$ & -0.0225 & 0.0024 & 0.0062 & 0.0139 & -0.0225 & 0.0024 & 0.0062 & 0.0139 & -0.0225 & 0.0048 & 0.0078 & 0.0100 \\
\hline Acquisition $^{\mathrm{a}}$ & 0.0832 & -0.0066 & -0.0261 & -0.0505 & 0.0832 & -0.0066 & -0.0261 & -0.0505 & 0.0832 & -0.0066 & -0.0261 & -0.0505 \\
\hline Joint-venture $^{\mathrm{a}}$ & 0.0556 & -0.0071 & -0.0165 & -0.0320 & 0.0556 & -0.0071 & -0.0165 & -0.0320 & 0.0541 & -0.0126 & -0.0191 & -0.0223 \\
\hline Subsidiary innovativeness & -0.0657 & 0.0176 & 0.0233 & 0.0248 & -0.0657 & 0.0176 & 0.0233 & 0.0248 & -0.0479 & 0.0127 & 0.0175 & 0.0177 \\
\hline
\end{tabular}

a Dummy variables are set at the median and continuous variables at the mean.

\section{References}

Ambos, B., Schlegelmilch, B.B., 2007. Innovation and control in the multinational firm: a comparison of political and contingency approaches. Strategic Management Journal 28, 473-486.

Ambos, T.C., Ambos, B., Schlegelmilch, B.B., 2006. Learning from foreign subsidiaries: an empirical investigation of headquarters' benefit from reverse knowledge transfers. International Business Review 15, 294-312.

Anand, J., 2011. Permeability to inter- and intrafirm knowledge flows: the role of coordination and hierarchy in MNEs. Global Strategy Journal 1 (3-4), 283-

300. Anand, J., Delios, A., 2002. Absolute and relative resources as determinants of international acquisitions. Strategic Management Journal 23, 119-134.

Andersson, U., Forsgren, M., Holm, U., 2002. The strategic impact of external networks: subsidiary performance and competence development in the multinational corporation. Strategic Management Journal 23, 979-996.

Andersson, U., Forsgren, M., Holm, U., 2007. Balancing subsidiary influence in the federative MNC: a business network view. Journal of International Business Studies 38, 802-818.

Bartlett, C.A., Ghoshal, S., 1989. Managing Across Borders: the Transnational Solution. Harvard Business School Press, Boston.

Benito, G.R.G., Grøgaard, B., Narula, R., 2003. Environmental influences on MNE subsidiary roles: Economic integration and the Nordic countries. Journal of International Business Studies 34, 443-456.

Birkinshaw, J., Hood, N., 1998. Multinational subsidiary evolution: capability and charter change in foreign-owned subsidiary companies. Academy of Management Review 23 (4), 773-795.

Björkman, I., Barner-Rasmussen, W., Li, L., 2004. Managing knowledge transfer in MNCs: the impact of headquarters control mechanisms. Journal of International Business Studies 35, 443-455.

Blomkvist, K., Kappen, P., Zander, I., 2010. Quo vadis? The entry into new technologies in advanced foreign subsidiaries of the multinational enterprise. Journal of International Business Studies 41, 1525-1549.

Blomkvist, K., Zander, I., Kappen, P., 2014. Win, place, or show? How foreign market entry strategies contribute to the technological growth of the multinational corporation. Long Range Planning $47(1-2), 16-31$.

Bouquet, C., Birkinshaw, J., 2008. Weight versus voice: how foreign subsidiaries gain attention from corporate headquarters. Academy of Management Journal 51, 577-601. 
Brett, J.F., Cron, W.L., Slocum Jr., J.W., 1995. Economic dependency on work: a moderator of the relationship between organizational commitment and

performance. Academy of Management Journal 38 (1), 261-271.

Brouthers, K.D., Hennart, J.-F., 2007. Boundaries of the firm: insights from international entry mode research. Journal of Management 33, 395-425. Brusoni,

S., Prencipe, A., Pavitt, K.L.R., 2001. Knowledge specialization, organizational coupling, and the boundaries of the firm: why do firms know more

than they make? Administrative Science Quarterly 46, 597-621.

Cantwell, J.A., 1995. The globalisation of technology: what remains of the product cycle model? Cambridge Journal of Economics 19, 155-174. Cantwell,

J.A., Piscitello, L., 1999. The emergence of corporate international networks for the accumulation of dispersed technological competences. Management International Review 39, 123-147.

Cantwell, J.A., Piscitello, L., 2000. Accumulating technological competence: its changing impact on corporate diversification and internationalisation. Industrial and Corporate Change 9, 21-51.

Cantwell, J.A., Mudambi, R., 2005. MNE competence-creating subsidiary mandates. Strategic Management Journal 26 (12), $1109-1128$.

Cantwell, J.A., Mudambi, R., 2011. Physical attraction and the geography of knowledge sourcing in multinational enterprises. Global Strategy Journal 1 (3-

4),

$206-232$.

Ciabuschi, F., Dellestrand, H., Martín Martín, O., 2011. Internal embeddedness, headquarters involvement, and innovation performance in multinational enterprises. Journal of Management Studies 48, 1612-1639.

Criscuolo, P., Narula, R., 2007. Using multi-hub structures for international R\&D: Organisational inertia and the challenges of implementation. Management International Review 47, 639-660.

Dellestrand, H., 2011. Orchestrating Innovation in the Multinational Enterprise: Headquarters Involvement in Innovation Transfer Projects. Ph.D.

Disser-

tation. Uppsala University.

Dierickx, I., Cool, K., 1989. Asset stock accumulation and sustainability of competitive advantage. Management Science 35, $1504-1511$.

Downey, K.H., Hellriegel, D., Slocum, J.W.J., 1975. Environmental uncertainty: the construct and its application. Administrative Science Quarterly 20,

613-

629.

Dunning, J.H., Narula, R., 1995. The R\&D activities of foreign firms in the United States. International Studies of Management and Organisation 25, 39-73.

Forsgren, M., Pedersen, T., 2000. Subsidiary influence and corporate learning: Centers of excellence in Danish foreign-owned firms. In: Holm, U., Pedersen, T. (Eds.), The Emergence and Impact of MNC Centers of Excellence. Macmillan, London.

Foss, N.J., Pedersen, T., 2002. Transferring knowledge in MNCs: the role of sources of subsidiary knowledge and organization context. Journal of International Management 8 (1), 49-67.

Foss, N.J., Foss, K., Nell, P., 2012. MNC organizational form and subsidiary motivation problems: controlling intervention hazards in the network MNC. Journal of International Management 18 (3), 247-259.

Frost, T.S., Zhou, C., 2005. R\&D co-practice and 'reverse' knowledge integration in multinational firms. Journal of International Business Studies 36, 676-687.

Ghoshal, S., Bartlett, C.A., 1988. Creation, adoption, and diffusion of innovations by subsidiaries of multinational corporations. Journal of International Business Studies 19, 365-388.

Ghoshal, S., Nohria, N., 1989. Internal differentiation within the multinational corporation. Strategic Management Journal 10, 323-337.

Ghoshal, S., Korine, H., Szulanski, G., 1994. Interunit communication in multinational corporations. Management Science 40, $96-110$.

Grant, R.M., 1996. Toward a knowledge-based theory of the firm. Strategic Management Journal 17, $109-122$.

Gupta, A.K., Govindarajan, V., 2000. Knowledge flows within multinational corporations. Strategic Management Journal 21, $473-496$.

Håkanson, L., Nobel, R., 2000. Technology characteristics and reverse technology transfer. Management International Review 40, $29-48$.

Håkanson, L., Nobel, R., 2001. Organization characteristics and reverse technology transfer. Management International Review 41, $392-420$.

Harman, H.H., 1967. Modern Factor Analysis. University of Chicago Press, Chicago, IL.

Hedlund, G., 1986. The hypermodern MNC - a heterarchy? Human Resource Management 25, 9-25.

Holm, U., Pedersen, T., 2000. The Emergence and Impact of MNC Centres of Excellence. MacMillan, Basingstoke.

Kappen, P., 2011. Competence-creating overlaps and subsidiary technological evolution in the multinational corporation. Research Policy 40, 673-686.

Kogut, B., Singh, H., 1988. The effect of national culture on the choice of entry mode. Journal of International Business Studies $19,411-432$.

Kogut, B., Zander, U., 1993. Knowledge of the firm and the evolutionary theory of the multinational corporation. Journal of International Business Studies 24 , $625-645$.

Kuemmerle, W.T.J., 1999. The drivers of foreign direct investment into research and development: an empirical investigation. Journal of International Business Studies 30, 1-24.

Lorenzen, M., Mudambi, R., 2013. Clusters, connectivity and catch-up: Bollywood and Bangalore in the global economy. Journal of Economic Geography 13 (3), 501-534.

Mariotti, S., Mutinelli, M., 2005. Italia multinazionale 2004. Le partecipazioni Italiane all'estero e estere in Italia. Rubbettino Editore, Soveria Mannelli.

Meyer, K.E., Mudambi, R., Narula, R., 2011. Multinational enterprises and local contexts: the opportunities and challenges of multiple embeddedness. Journal of Management Studies 48 (2), 235-252.

Minbaeva, D., 2007. Knowledge transfer in multinational corporations. Management International Review 47, $567-593$.

Monteiro, F.L., Arvidsson, N., Birkinshaw, J., 2008. Knowledge flows within multinational corporations: explaining subsidiary isolation and its performance implications. Organization Science 19, 90-107.

Morck, R., Yeung, B., 1991. Why investors value multinationality. Journal of Business 64, 165-187.

Mudambi, R., 2008. Location, control and innovation in knowledge-intensive industries. Journal of Economic Geography 8, 699-725.

Mudambi, R., 2011. Hierarchy, coordination and innovation in the multinational enterprise. Global Strategy Journal 1, $317-323$.

Mudambi, R., Navarra, P., 2004. Is knowledge power? Knowledge flows, subsidiary power and rent-seeking within MNCs. Journal of International Business Studies 35, 385-406.

Mudambi, R., Swift, T., 2011. Proactive R\&D management and firm growth: a punctuated equilibrium model. Research Policy 40, 429-440.

Mudambi, R., Swift, T., 2013. Knowing when to leap: transitioning between exploitative and explorative R\&D. Strategic Management Journal. http://dx.doi. org/10.1002/smj.2097 forthcoming.

Mudambi, R., Schründer, C.P., Mongar, A., 2004. How cooperative is cooperative purchasing in smaller firms? Evidence from UK engineering SMEs. Long Range Planning 37, 85-102.

Narula, R., 2002. Innovation systems and 'inertia' in R\&D location: Norwegian firms and the role of systemic lock-in. Research Policy 31, 795-816. Narula, R.,

Santangelo, G.D., 2009. Location, collocation and R\&D alliances in the European ICT industry. Research Policy 38, $393-403$.

Nielsen, B.B., Michailova, S., 2007. Knowledge management systems in multinational corporations: typology and transitional dynamics. Long Range Planning 40, 314-340.

Nohria, N., Ghoshal, S., 1994. Differentiated fit and shared values: alternatives for managing headquarters-subsidiary relations. Strategic Management Journal 15, 491-502.

Noorderhaven, N., Harzing, A.-W., 2009. Knowledge-sharing and social interaction within MNEs. Journal of International Business Studies 40, 719-741.

Palmie, M., Keupp, M., 2014. Pull the right levers: creating useful subsidiary competence by appropriate organizational architecture. Long Range Planning 47 $(1-2), 32-48$.

Papanastassiou, M., Pearce, R.D., 1997. Technology sourcing and the strategic roles of manufacturing subsidiaries in the U.K.: local competences and global competitiveness. Management International Review 37 (1), 5-25.

Pavitt, K.L.R., 1984. Sectoral patterns of technical change: towards a taxonomy and a theory. Research Policy 13, 343-373.

Pavitt, K.L.R., 1990. What we know about the strategic management of technology. California Management Review 32, 17-26.

Pearce, R.D., 1997. Global competition and technology: essays in the creation and application of knowledge by multinationals. Macmillan, London. 
Pearce, R.D., 1999. The evolution of technology in multinational enterprises: the role of creative subsidiaries. International Business Review 8, 125-148.

Penrose, E., 1959. The theory of the growth of the firm. Basil Blackwell, Oxford, England.

Podsakoff, P.M., MacKenzie, S.B., Podsakoff, N.P., 2003. Common method biases in behavioral research: a critical review of the literature and recommended

remedies. Journal of Applied Psychology 88, 879-903.

Porter, M.E., 1990. The competitive advantage of nations. Free Press, New York.

Rabbiosi, L., 2011. Subsidiary roles and reverse knowledge transfer: an investigation of the effects of coordination mechanisms. Journal of International

Management 17, 97-113.

Rabbiosi, L., Santangelo, G.D., 2013. Parent company's benefits from reverse knowledge transfer: the role of the liability of newness in MNEs. Journal of World Business 48 (1), 160-170.

Rugman, A.M., Verbeke, A., 2001. Subsidiary-specific advantages in multinational enterprises. Strategic Management Journal 22, 237-250.

Rugman, A.M., Verbeke, A., Yuan, W., 2011. Re-conceptualizing Bartlett and Ghoshal's classification of national subsidiary roles in the multinational enterprise. Journal of Management Studies 48 (2), 253-277.

Sambharya, R., 1996. Foreign experience of top management teams and international diversification strategies of U.S. multinational corporations. Strategic Management Journal 17, 739-746.

Schulz, M., 2001. The uncertain relevance of newness: organizational learning and knowledge flows. Academy of Management Journal 44, 661-681.

Spulber, D., 2009. The theory of the firm. Cambridge University Press, New York.

Subramaniam, M., Venkatraman, V.N., 2001. Determinants of transnational new product development capability: testing the influence of transferring and deploying tacit knowledge. Strategic Management Journal 22, 359-378.

Tallman, S.B., Phene, A., 2007. Leveraging knowledge across geographic boundaries. Organization Science 18, 252-260.

Tsai, W., 2002. Social structure of "Coopetition" within a multiunit organization: coordination, competition, and intraorganizational knowledge sharing.

Organization Science 13, 179-190

Venaik, S., Midgley, D.F., Devinney, T.M., 2005. Dual paths to performance: the impact of global pressures on MNC subsidiary conduct and performance.

Journal of International Business Studies 36, 655-675.

Vernon, R., 1966. International investment and international trade in the product cycle. Quarterly Journal of Economics 80, 190-207.

Williams, C., 2007. Transfer in context: replication and adaptation in knowledge transfer relationships. Strategic Management Journal 28, 867-889. Yang, Q.,

Mudambi, R., Meyer, K., 2008. Conventional and reverse knowledge flows in multinational corporations. Journal of Management 34, 882-902. Zander, I.

1998. The evolution of technological capabilities in the multinational corporation-dispersion, duplication and potential advantages from multinationality. Research Policy 27, 17-35.

Zander, I., 1999. How do you mean 'global'? An empirical investigation of innovation networks in the multinational corporations. Research Policy 28,

$195-213$.

\section{Biographies}

Ram Mudambi is a Professor and Perelman Senior Research Fellow at the Fox School of Business, Temple University, USA, and a Visiting Professor at the University of Reading Business School. His research focuses on the geography of innovation, knowledge management and strategic entrepreneurship. He holds a Ph.D. from Cornell University, and has been a Visiting Professor at Bocconi University in Milan, Italy, and Copenhagen Business School, among others. His work has appeared in Journal of Political Economy, Strategic Management Journal, Strategic Entrepreneurship Journal and Journal of Economic Geography, among others. E-mail: ram.mudambi@temple.edu

Lucia Piscitello is a Professor at the Politecnico di Milano, Italy. Her research focuses on the management of technology in the context of multinational enterprises. She holds a Ph.D. from the Politecnico di Milano, and has been a Visiting Professor at Rutgers Business School in New Jersey, USA. Her work has appeared in Journal of Economic Geography, Industrial and Corporate Change and Strategic Entrepreneurship Journal, among many others. E-mail: lucia. piscitello@polimi.it

Larissa Rabbiosi is an Associate Professor at the Department of International Economics and Management at Copenhagen Business School. She holds a Ph.D. from the Politecnico di Milano. Her work has appeared in Industrial and Corporate Change, Journal of International Management and Management International Review, among others. E-mail: lr.int@cbs.dk 